\title{
The effects of ECG characteristics on 3-month mortality in patients with acute coronary syndrome
}

\author{
Abdullah Osman Kocak* \\ Ataturk University, Medical School, Depertment of Emergency Medicine, Turkey
}

\begin{abstract}
Introduction: Acute Coronary Syndrome (ACS) is a clinical condition caused by ischemia of the heart tissue due to decrease in blood flow in the coronary arteries. It is classified into three groups in Electrocardiography (ECG) as follows; ST-Elevation Myocardial Infarction (STEMI), Non-ST Elevation Myocardial Infarction (NSTEMI) with elevation of enzyme and myocardial infarction unstable angina (UA) with minimal cell damage, no enzyme elevation and no change in ECG.

Material and method: This study is a retrospective study performed between 01.01.2016 and 31.12.2017 at Atatürk University Medical Faculty Hospital Emergency Service. In this study, patients over 18 years of age, who went to Atatürk University Medical Faculty Hospital Emergency Service with symptoms of ACS and hospitalized in cardiology clinic were included. Patients were obtained by file scanning.

Result: Of the patients included in the study, 58 (29.4\%) were female. Regarding the complaints in admission, the most common reason for admission was chest pain $(\mathrm{n}=184,93.4 \%) .21$ patients had dyspnea and 8 patients had palpitation complaints. When we look at patients' previous diseases, diabetes $(\mathrm{n}=62,31.5 \%)$ is the most common among them. Other diseases were as follows; 47 patients with pre-coronary artery disease, 30 patients with bypass surgery, 28 patients with heart failure, 21 patients with hypertension, 17 patients with ischemic stroke, 14 patients with COPD, and 11 patients with chronic renal failure. ECG findings of patients were as follows; ST Elevation $(n=79)$, ST Depression ( $n=35)$, T negativity $(n=58)$, Left bundle branch block $(n=7)$, Rhythm disorder $(n=15)$, Atrial fibrillation $(n=10)$
\end{abstract}

Conclusion: In our study, we aimed to investigate mortality according to ECG characteristics, and no effect of ECG findings on mortality, other than ST elevation, was confirmed.

\section{Introduction}

Acute Coronary Syndrome (ACS) is a clinical condition caused by ischemia of the heart tissue due to decrease in blood flow in the coronary arteries. It is classified into three groups in Electrocardiography (ECG) as follows; ST-Elevation Myocardial Infarction (STEMI), Non-ST Elevation Myocardial Infarction with elevation of enzyme (NSTEMI) and myocardial infarction unstable angina (UA) with minimal cell damage, no enzyme elevation and no change in ECG [1]. In acute coronary syndromes, crieteria such as increased ischemic symptoms within 48 hours, resting pain lasting more than 20 minutes, pulmonary edema due to ischemia, murmur of new or deteriorating mitral regurgitation, S3 or newly developing ral, hypotension, tachycardia, bradycardia, age above 75 , more than $0.5 \mathrm{~mm}$ ST-segment changes in the ECG, newly developed left bundle branch block, ventricular tachycardia, troponin $\mathrm{I}>0.1 \mathrm{ng} / \mathrm{ml}$ indicate that patients are at high risk and the prognosis will be poor [2]. Coronary Artery Disease (CAD) is the most common cause of death in the world and in our country. Cardiovascular diseases are responsible for deaths of $45 \%$ of women and $38 \%$ of men under 75 years of age in Europe [3]. These are followed by cancer diseases [4].

Atherosclerosis is the process of plaque formation involving the intima of large and medium-sized arteries. It proceeds troughout the human life. Coronary risk factors such as hypercholesterolemia, hypertension, diabetes and smoking are effective in this process $[5,6]$.

These risk factors damage the vascular endothelium and play an important role in the initiation of the atherosclerotic process. Nitric oxide and endothelin-1 production, overproduction of adhesion molecules (selectins, vascular cell adhesion molecules and intercellular adhesion molecules) and the release of several local substances increases the tendency for thrombosis in the blood $[7,8]$.

After the endothelium is damaged, especially inflammatory cells such as monocytes connect to the endothelial adhesion molecules, migrate to the subendothelium and differentiate into macrophages. Macrophages convert oxidized low-density lipoprotein (LDL) into foam cells and allow the formation of fat lines. Activated macrophages provide chemoattractant and cytokines, matrix metalloproteinases, and preparation of enzymes that cause plaque degradation. The ratio between smooth muscle cells and macrophages plays an important role in plaque rupture. 99\% of cases occur due to plaque rupture [9].

Even the content of atherosclerotic plaques in different regions differs from each other. Inflammation is an important determinant of the instability of plaques [10]. It causes expansion of the lipid core,thinning of the plaque and plaque rupture due to increased activity in macrophages. Elevation of C-reactive protein (CRP) levels is important in demonstrating the activity of macrophages [11].

The pathogenesis of ACS involves a complex interaction between endothelium, inflammatory cells and blood thrombosis [12]. In two-

${ }^{\star}$ Correspondence to: Abdullah Osman Kocak, Ataturk University Medical School Depertment of Emergency Medicine, Erzurum,Turkey; Tel: +90544 56671 58; Fax: +90 44223131 33; E-mail: abdullahmrym86@gmail.com

Received: January 21, 2019; Accepted: January 31, 2019; Published: February 31,2019 
thirds of ACS cases with angiographically $\geq 50 \%$ stenosis in vascular diameter, non-critical lesions may cause severe or complete obstruction [13].

In studies performed with intravascular ultrasonography, at least $80 \%$ of patients with ACS were found to have rupture of different plaques [14].

Autopsy studies have shown that plaque rupture is responsible for $75 \%$ of fatal MIs. Superficial endothelial erosion is responsible for the remaining $\% 25$ [15].

\section{Material and method}

This study is a retrospective study performed between 01.01.2016 and 31.12.2017 at Atatürk University Medical Faculty Hospital Emergency Service. In this study, patients over 18 years of age who were admitted to Atatürk University Medical Faculty Hospital Emergency Service with symptoms of ACS(chest pain, shortness of breath, palpitations, back pain, etc.) and hospitalized in cardiology clinic were included. Patients were obtained by file scanning. Patients with incomplete or incorrect information were excluded from the study.

Age, gender, complaints of the patients, duration of pain before application (in hours), previous diseases, vital signs (blood pressure, pulse, oxygen saturation), ECG characteristics, patient diagnosis, condition of angiography, length of stay and 3 months mortality status of the patients were analyzed. Mortality conditions were learned by calling the registered phone in the hospital automation system. Patients who could not be reached by phone were not included in the study.

- Inclusion criteria;

1) Patients over 18 years old

2) Patients presenting with symptoms that suggest ACS and hospitalized in the cardiology clinic

3) Patients with stable vital signs.

- Exclusion criteria;

1) Patients with missing data in file

2) Patients who cannot be reached by phone

3) Patients with unstable vital signs.

4) Patients with cardiopulmonary arrest on arrival

5) Intubated patients

6) Patients with respiratory support

Statistical Package for Social Sciences (SPSS. 20) package programwas used for statistical analysis. Paired-sample t test was used to compare the normally distributed dependent variables. All data were expressed as mean \pm standard deviation and $\mathrm{p}<0.05$ was considered statistically significant.

\section{Result}

1903 patients were hospitalized from the emergency department to the cardiology clinic. After the inclusion and exclusion criteria were applied, our study was completed with 197 patients. Patient demographic data, vital signs and duration of hospitalization are shown in Table 1.

Of the patients included in the study, 58 (29.4\%) were female. Regarding the complaints in admission, the most common reason for admission was chest pain $(\mathrm{n}=184,93.4 \%) .21$ patients had dyspnea and 8 patients had palpitation complaints. When we look at patients' previous diseases, diabetes $(n=62,31.5 \%)$ is the most common among them. Other diseases included 47 patients with pre-coronary artery disease, 30 patients with bypass surgery, 28 patients with heart failure, 21 patients with hypertension, 17 patients with ischemic stroke, 14 patients with COPD, and 11 patients with chronic renal failure. ECG findings of patients are summarized in Table 2.

Of the patients, 77 (39.1\%) were diagnosed with STEMI, 92 (46.7\%) with NSTEMI, and 28 (14.2\%) were diagnosed with unstable angina pectoris. Coronary angiography was performed in $84.3 \%(n=166)$ of our patients. Of the 197 patients, 20 (10.2\%) died within 3 months of admission.

There was a statistically significant relationship between age, systolic blood pressure and oxygen saturation with 3 months mortality $(\mathrm{p}<0.05)$. There was no statistical difference between the onset of the complaint, diastolic blood pressure, pulse and hospitalization time with 3-month mortality ( $>0.05$ ). While the mean age of the patients who died within 3 months was 70.65 and the mean age of the patients who did not die was 60.5 years; it shows the effect of advanced age on mortality in this case. While oxygen saturation was determined an average of $87,95 \%$ in the patients who died within 3 months, the average of the patients who did not die was $92,38 \%$. In this case it is seen that hypoxic patients have a worse prognosis. In terms of systolic blood pressure, while the mean value of the patients who died within 3 months was $127.25 \mathrm{mmHg}$, the mean blood pressure of the patients who did not die was $140.55 \mathrm{mmHg}$. Although these values are in the normal range and clinically insignificant, low systolic blood pressure may make the mortality more predisposed. There was no relationship between sex and 3-month mortality ( $p>0.05)$. When the complaints of the patients were examined, 3 months mortality was higher in patients with dyspnea and this was statistically significant $(\mathrm{p}<0.05) .25 \%$ of patients who died within 3 months complained of shortness of breath. Only 16 of 177 patients who did not die had dyspnea.

When the patients' previous diseases were examined, only the patients with ischemic stroke had a significant relation with mortality ( $\mathrm{p}<0.05$ ). Of the 20 patients who died within 3 months, 5 had previous SVO. Only 12 of 177 living patients had SVO. There was no relationship between mortality and other previous diseases ( $p>0.05)$.

According to ECG characteristics, only ST elevation was found to have a statistically significant relation with 3-month mortality ( $\mathrm{p}$

Table 1. Patient data

\begin{tabular}{|l|c|c|c|c|}
\hline & Mean & $\begin{array}{c}\text { Std. } \\
\text { Deviation }\end{array}$ & Minimum & Maximum \\
\hline Age & 61,53 & 13,706 & 21 & 93 \\
\hline Duration of Complaint (Hour) & 44,55 & 276,666 & 0 & 3600 \\
\hline Systolic Blood Pressure (mmHg) & 139,20 & 28,048 & 50 & 250 \\
\hline Diastolic Blood Pressure (mmHg) & 85,66 & 55,853 & 30 & 820 \\
\hline Oxygen Saturation (\%) & 91,93 & 5,948 & 40 & 100 \\
\hline Heart Rate(dk) & 81,26 & 16,661 & 46 & 132 \\
\hline Hospitalization(Day) & 6,22 & 4,734 & 0 & 37 \\
\hline
\end{tabular}

Table 2. ECG findings of patients

\begin{tabular}{|c|c|}
\hline ST Elevation & $\mathrm{n}=79(\% 40,1)$ \\
\hline ST Depression & $\mathrm{n}=35(\% 17,8)$ \\
\hline T Wave Negativity & $\mathrm{n}=58(\% 29,4)$ \\
\hline Left Branch Block & $\mathrm{n}=7(\% 3,6)$ \\
\hline Arrhythmia & $\mathrm{n}=15(\% 7,6)$ \\
\hline Atrial Fibrillation & $\mathrm{n}=10(\% 5,1)$ \\
\hline
\end{tabular}


$<0.05)$. While 13 of 20 deceased patients had ST elevation, ST elevation was present in 66 of the 177 patients who did not die. There was no statistically significant correlation between other ECG findings (ST Depression, T negativity, Left bundle branch block, Rhythm disorder, Atrial fibrillation) and 3-month mortality ( $p>0.05)$. The 3-month mortality rate was statistically significant in STEMI patients, as expected. $(\mathrm{p}<0.05)$. There was no statistically significant relationship between mortality and coronary angiography $(\mathrm{p}>0.05)$.

\section{Discussion}

ACS is a syndrome that is occurring more and more every day and should be paid attention carefully considering the results. Early diagnosis of ACS is important. Because, this patient group has a death rate of about $50 \%$ in the first month and half of these deaths occur within the first two hours and outside the hospital. While the most common cause of death before hospital was arrhythmia, it was found that the most common cause of death in the hospital was heart failure. While the in-hospital mortality rate is $16 \%$ before reperfusion applications, early treatments of myocardial ischemia such as fibrinolysis, percutaneous coronary intervention and coronary artery bypass graft positively affects the prognosis after AMI. This rate is around 4-6\% with these new treatments $[16,17]$. Early treatment and risk classification are important [18]. The ACC / AHA guidelines also recommend that the risk classification in ACS should be performed previously and precisely [19]. In the GRACE study, which is a clinically predictive study of patients presenting with ACS, with a 6-month mortality and likelihood of relapsing ACS, 17,142 patients were included between 1999 and 2002. During this period, $4.8 \%$ of the patients died within a six-month period and as a result of this study, age, heart rate, systolic blood pressure, history of peripheral arterial disease, serum creatine value at the time of application, heart failure history, Killip class, ECG ST segment depression, elevation in cardiac biomarkers and cardiac arrest status of the patient were used as risk factors [20]. In our study, age, systolic blood pressure, oxygen saturation, past ischemic SVO and ST segment elevation were found to be associated with 3-month mortality. In addition to these parameters, it has been suggested that gender may be a risk factor. When the sex was examined as a risk factor, more ACS patients were found in the male population. In the study of Grundy et al. [21], the frequency of ACS female/male ratio (F/M) was determined as $1 / 7$. While STEMI is more common in males, NSTEMI is more common in females [22]. Of the 197 patients included in our study, 139 (70.6\%) were male and the F/M ratio was approximately 2/5. This result, which is consistent with the literature, is considered to be due to the protective effect of the estrogen hormone in female sex. In the literature, it is stated that one of the most important risk factors in patients with ACS is age. The mean age in the Leurent et al. [23] study was $62.6 \pm 13$ years, in the Ariza-Sole et al. [24] study it was $62.1 \pm 12$ years and in the Muhammed et al. [25] study it was $62.83 \pm 12.9$ years. Although ACS is seen in the younger population, it is still accepted as an elderly disease. In our study, it is $61.53 \pm 13.7$.

According to the Euro Heart Survey-Acute Coronary Syndromes study, approximately half of all ACS (48\%) constitute STEMI [26]. There has been a decline in ST elevation ACS over the years [19]. In our study, this ratio is compatible with the literature with $39.1 \%$. Although the inhospital mortality of STEMI is higher than NSTEMI, the mortality rates of 6 months are similar. In the long term, NSTEMI is found to have a higher mortality [27].

When ECG of ACS patients were evaluated, Gibler et al. [28] determined normal sinus rhythm in $64 \%$ of the patients with ACS in the emergency service. In Bozkurt et al.s [29] study, 19.4\% normal sinus rhythm, 20.8\% ST elevation, 22.3\% pathological Q and $25 \%$ ST depression was found. In our study, ST Elevation was found in 79 (40.1\%), ST depression in $35(17.8 \%)$, T negativity in 58 (29.4\%), left bundle branch block in 7 (3.6\%), rhythm disorder in 15 (7.6\%), AF rhythm in $10(5.1 \%)$ of the patients. Since the patient groups included in the studies were different, we believe that ECG findings may differ from each other.

\section{Conclusion}

In our study, we aimed to investigate mortality according to ECG characteristics, and no effect of ECG findings on mortality, other than ST elevation, was confirmed.

\section{References}

1. Braunwald E, Antman EM, Beasley JW, Califf RM, Cheitlin MD, et al. (2000) ACC AHA guidelines for the management of patients with unstable angina and nonST-segment elevation myocardial infarction. A report of the American College of Cardiology/American Heart Association Task Force on Practice Guidelines (Committee on the Management of Patients With Unstable Angina). J Am Coll Cardiol 36: 9701062. [Crossref]

2. Yıldız A, Pehlivanoğlu S, Gürmen T, Coşkun U, Kılıçkesmez KO, et al. (2011) Correlation between the AHCPR (Agency For Health Care Policy and Research) risk stratification and angiographic morphology in non-ST-segment elevation acute coronary syndrome. Turk Kardiyol Dern Ars 39: 105-113. [Crossref]

3. Network (2012) EH. European Cardiovascular Disease Statistics.

4. Turkey Statistical Institute data for 2010.http://www.tuik.gov.tr. date of access 01.01.2019

5. Fuster V, Badimon L, Cohen M, Ambrose JA, Badimon JJ, et al. (1988) Insights into the pathogenesis of acute ischemic syndromes. Circulation 77: 1213-1220. [Crossref]

6. Libby P (2001) Current concepts of the pathogenesis of the acute coronary syndromes. Circulation 104: 365-372. [Crossref]

7. Corti R, Fuster V, Badimon JJ, Hutter R, Fayad ZA (2001) New understanding of atherosclerosis (clinically and experimentally) with evolving MRI technology in vivo. Ann N Y Acad Sci 947: 181-195. [Crossref]

8. Kinlay S, Libby P, Ganz P (2001) Endothelial function and coronary artery disease. Curr Opin Lipidol 12: 383-389. [Crossref]

9. Webster MWI CJ, Smith HC (1990) Myocardial infarction and coronary artery occlusion: a prospective 5-year angiographic study. J Am Coll Cardiol 15: 218A.

10. Lendon CL, Davies MJ, Born GV, Richardson PD (1991) Atherosclerotic plaque caps are locally weakened when macrophages density is increased. Atherosclerosis 87: 8790. [Crossref]

11. Sano T, Tanaka A, Namba M, Nishibori Y, Nishida Y, et al. (2003) C-reactive protein and lesion morphology in patients with acute myocardial infarction. Circulation 108: 282-285. [Crossref]

12. Naghavi M, Libby P, Falk E, Casscells SW, Litovsky S, et al. (2003) From vulnerable plaque to vulnerable patient: a call for new definitions and risk assessment strategies: Part I. Circulation 108: 1664-1672. [Crossref]

13. Luscher TF, Tanner FC, Noll G (1996) Lipids and endothelial function: effects of lipidlowering and other therapeutic interventions. Curr Opin Lipidol 7: 234-240.

14. Rioufol G, Finet G, Ginon I, Andre-Fouet X, Rossi R, et al. (2002) Multiple atherosclerotic plaque rupture in acute coronary syndrome: a three-vessel intravascular ultrasound study. Circulation 106: 804-808. [Crossref]

15. Davies MJ (1990) A macro and micro view of coronary vascular insult in ischemic heart disease. Circulation 82: II38-46. [Crossref]

16. Investigators AA, Armstrong PW, Granger CB, Adams PX, Hamm C, et al. (2007) Pexelizumab for acute ST-elevation myocardial infarction in patients undergoing primary percutaneous coronary intervention: a randomized controlled trial. JAMA 297: 43-51.

17. Assessment of the S, Efficacy of a New Treatment Strategy with Percutaneous Coronary Intervention. (2006) Primary versus tenecteplase-facilitated percutaneous coronary intervention in patients with ST-segment elevation acute myocardial infarction (ASSENT-4 PCI): randomised trial. Lancet 367: 569-578. [Crossref] 
18. Afzali D, Erren M, Pavenstdt HJ, Vollert JO, Hertel S, et al. (2013) Impact of copeptin on diagnosis, risk stratification, and intermediate-term prognosis of acute coronary syndromes. Clin Res Cardiol 102: 755-763. [Crossref]

19. (1994) Effects of tissue plasminogen activator and a comparison of early invasive and conservative strategies in unstable angina and non-Q-wave myocardial infarction. Results of the TIMI IIIB Trial. Thrombolysis in Myocardial Ischemia. Circulation 89:1545-1556. [Crossref]

20. Eagle KA LM, Dabbous OH, Pieper KS (2004) A validated prediction model for all forms of acute coronary syndrome: estimating the risk of 6-month postdischarge death in an international registry. JAMA 291:2727-2733. [Crossref]

21. Grundy SM, Pasternak R, Greenland P, Smith S, Jr, Fuster V (1999) AHA/ACC scientific statement: Assessment of cardiovascular risk by use of multiple-risk-factor assessment equations: a statement for healthcare professionals from the American Heart Association and the American College of Cardiology. J Am Coll Cardiol 34: 1348-1359. [Crossref]

22. Fox KA, Eagle KA, Gore JM, Steg PG, Anderson FA; GRACE and GRACE2 Investigators (2010) The Global Registry of Acute Coronary Events, 1999 to 2009--GRACE. Heart 96: 1095-1101. [Crossref]

23. Leurent G, Garlantzec R, Auffret V, Hacot JP, Coudert I, et al. (2014) Gender differences in presentation, management and inhospital outcome in patients with STsegment elevation myocardial infarction: data from 5000 patients included in the ORB prospective French regional registry. Arch Cardiovasc Dis 107: 291-298. [Crossref]
24. Ariza-Sole A, Formiga F, Lorente V, Sanchez-Salado JC, Sanchez-Elvira G, et al. (2014) Efficacy of bleeding risk scores in elderly patients with acute coronary syndromes. Rev Esp Cardiol (Engl Ed) 67: 463-470. [Crossref]

25. Muhammed Salama HA, Kahraman CoGansu, BariG Gkitimur, Bilgehan Karadag, Rasim Enar (2010) Akut koroner sendromlarda standart risk skorlamalariyla birlikte geliGteki NT-proBNP dzeyinin 6 aylik mortalite ve morbiditeye etkileri. Trk Kardiyol Dern Ars.

26. Mandelzweig L BA, Boyko V, Bueno H, Danchin N, Filippatos G, et al. (2006) The second Euro Heart Survey on acute coronary syndromes: Characteristics, treatment, and outcome of patients with ACS in Europe and the Mediterranean Basin in 2004. Eur Heart J 27: 2285-2293. [Crossref]

27. Yeh RW, Sidney S, Chandra M, Sorel M, Selby JV, et al. (2010) Population trends in the incidence and outcomes of acute myocardial infarction. $N$ Engl J Med 362: 2155 2165. [Crossref]

28. Gibler WB, Young GP, Hedges JR, Lewis LM, Smith MS, et al. (1992) Acute myocardial infarction in chest pain patients with nondiagnostic ECGs: serial CK-MB sampling in the emergency department. The Emergency Medicine Cardiac Research Group. Ann Emerg Med 21: 504-512. [Crossref]

29. (2006) SB The diagnostic and prognostic value of glycogen phosphorylase isoenzyme$\mathrm{BB}$ in the diagnosis of acute coronary syndrome in patients with chest pain.

Copyright: (2019 Kocak AO. This is an open-access article distributed under the terms of the Creative Commons Attribution License, which permits unrestricted use, distribution, and reproduction in any medium, provided the original author and source are credited. 